\title{
Research \\ Frames of Scale Challenges in Finnish and Greek Biodiversity Conservation
}

\author{
Evangelia Apostolopoulou ${ }^{\text {and Riikka Paloniemi }}{ }^{2}$
}

\begin{abstract}
Global conservation expansion has been associated with significant changes in cross-scale interactions and in the discourses surrounding them engendering new scale challenges in the field of biodiversity conservation. In this paper, we analyze frames of scale challenges by drawing on evidence from eight focus groups of stakeholders and scientists from Greece and Finland. By following a systematic frame analysis we found three dominant frames. First, framing scale challenges as mainly derived from knowledge gaps regarding ecological scale emphasizes the scale problems occurring when only limited consideration is given to the scale-dependence of ecological phenomena. This prioritizes the formulation of scientifically informed conservation policies, discounting the importance of governance by concentrating on specialized environmental administrations. Second, framing scale challenges as stemming from limited fit highlights the scale problems caused by discrepancies in the alignment of natural and social scales and underlines the need to optimize the match between ecological and governance levels with more or less fixed boundaries. Third, framing scale challenges as primarily derived from inequalities in existing power relationships and learning processes emphasizes scale problems resulting when the dominant perception of scale is seen as a neutral, technical issue. This calls for investigations focused explicitly on how conservation scaling contributes to the production of new social-ecological entities in space and time. Dialogues between aspects of the different frames offer a potential path toward deliberative learning aimed at resolving current contradictions in the spatial patterning of humanenvironment interactions produced by biodiversity conservation.
\end{abstract}

Key Words: biodiversity governance; conservation areas; fit; frames; learning; mismatch; power; scale

\section{INTRODUCTION}

In the dominant discourse on the importance of scale over the last two decades (Sayre 2008), one of the more significant contributions has been the well-known argument of Levin (1992:1961) that "the problem of relating phenomena across scales is the central problem in biology and in all of science." This era has witnessed an impressive increase in references to the importance of scale for environmental policy and governance design and performance (Termeer et al. 2010, Buizer et al. 2011, Kok and Veldkamp 2011), leading to issues related to scale, particularly cross-scale interactions, becoming acknowledged as key challenges (Cash et al. 2006). Unsurprisingly, the last decade has seen escalating problems stemming from a slew of scale mismatches attracting policy attention (MEA 2005, Ekstrom and Young 2009) as important causes of failures in natural resource management (Crowder et al. 2006, Cumming et al. 2006, Folke et al. 2007, Gabriel et al. 2010). These trends seem firmly related to the gradual emergence of a global agenda for environmental problems and earth system governance seen in the context of both rapid global environmental change such as climate change and global conservation expansion. The latter, as Zimmerer (2006) argues, comprises both spatial-environmental dimensions and the discourses and rhetoric permeating them.

Scale challenges have so far been investigated mainly in theoretical terms or via context-specific case studies. However, how stakeholders involved in biodiversity governance perceive, interpret, and frame scale challenges is still an open question, one of particular importance because it simultaneously reveals the interpretation schemes guiding policy debates and how current theoretical discussions and scientific knowledge claims regarding scale are transferred to the policy realm. Moreover, frames of scale challenges influence prioritization of scale problems and solutions affecting policy approaches, management strategies, and governance choices. The latter are of crucial importance in the politics of scale in which the negotiation of scales produced simultaneously by social and biophysical processes is at stake (McCarthy 2005).

Biodiversity conservation is an illuminating case for exploring scale challenges, given that biodiversity is by definition a multiscale phenomenon, and conservation expansion has at its core several emerging multiscalar challenges. At the EU level, the significant expansion of conservation areas, especially by the designation of the Natura 2000 network, through the increased inclusion of human-made landscapes in conservation efforts, sets social boundaries for the landscape directly influencing the spatial patterning of humanenvironment interactions. Environmental science supporting conservation planning can be characterized as scale-sensitive because conservation defines spatial scales of environmental institutions, changing how people interact materially with the objects of conservation (Turner 2006). 
Therefore, in this paper, we investigate frames of scale challenges in biodiversity conservation by focusing on the designation of conservation areas and management within them, and in surrounding areas, in two European countries, Finland and Greece (see Appendix I). 'Frames' refer to the process through which people involved in, for example, politics, seek to convince others of their perspectives on the world, how it should be, and how policies could be made more effective (McCann 2003); they constitute key issues in any cross-scale, interdisciplinary research (Ogunseitan 2003, Boykoff et al. 2010, Kok and Veldkamp 2011).

In particular, we ask the following research questions: (i) How do stakeholders acting at different governance levels in Finland and Greece frame the most urgent scale challenge of biodiversity conservation? (ii) Which specific scale-related problems and relevant solutions are considered most significant? (iii) Which conceptualizations of scale and the relationship between ecological and governance scales do these frames reflect? Finally, we discuss how the different frames influence transitions to "scale-sensitive" biodiversity governance, i.e., governance with potential to handle core scale challenges, acknowledge cross-scale interactions, and address the coproduction of ecological and social scales.

\section{THEORY}

\section{Scale and scale challenges}

Even though scale has been characterized as a concept with potential to integrate different disciplines (Cumming et al. 2006, Sayre 2008), and the need for common definitions of scale-related concepts has long been highlighted (e.g., Turner 1989), it is widely acknowledged that scale has many definitions and meanings (Gibson et al. 2000, McCarthy 2005, Cash et al. 2006, Neumann 2009, Buizer et al. 2011). This multiplicity of interpretations has produced a growing and diverse corpus on scaling rapidly attributing multiple meanings to notions of scale challenges in biodiversity governance.

Cash et al. (2006) argue that the three common scale challenges are: (1) the failure to recognize important scale and level interactions altogether, i.e., "ignorance", (2) the persistence of mismatches between levels and scales in humanenvironment systems, i.e., "mismatch," and (3) the failure to recognize heterogeneity in the way that scales are perceived and valued by different actors, i.e., "plurality." This description of scale challenges is based on an interdisciplinary definition of scale as the spatial, temporal, quantitative, or analytical dimension used to measure and study any phenomenon, and a definition of "levels" as the units of analysis located at different positions on a scale (Gibson et al. 2000, Cash et al. 2006). In describing these challenges prominence is given to understanding and handling cross-level and cross-scale interactions, matching human action and ecological systems, and unraveling why and how scale issues are related to politics. The explicit inclusion of the societal factor in the definition of scale challenges has stimulated the emergence of a new research paradigm (Kok and Veldkamp 2011) calling for cross-scale integrative methods considering both stakeholders (e.g., Baker et al. 2010) and the interrelationships between social and ecological systems (e. g., Cumming et al. 2006, Collins et al. 2011).

Simultaneously, a significant body of literature rooted in Marxist-influenced political ecology and geography focuses on scale challenges by exploring the politics of scale and approaching scale as socially constructed, historically contingent, and politically contested (Swyngedouw 1997, 2004, 2007, Smith 2000, Brenner 2001, McCarthy 2005, Zimmerer 2006, Görg 2007, Neumann 2009). Thus scale challenges are directly related to the fact that spatial scales are not natural units for social existence; rather their continuous deconstruction and reconstruction reshuffles power relationships (Swyngedouw 2000). In these fields, there have been significant efforts to define scale in an interdisciplinary and comprehensible way across field boundaries (Sayre 2005, 2008, Manson 2008, Neumann 2009) by approaching social and natural processes as dialectically intertwined (McCarthy 2005, Sayre 2005). As Swyngedouw (2007:11) argues, the production of socio-natures expresses and reconstitutes physical, social, cultural, economic, and political power relations; accordingly, scale is not ontologically given but "socio-environmentally mobilized through socio-spatial power struggles."

On the other hand, in ecology literature, scale is often defined as the extent and resolution of study regions, data, and areas of assessment (e.g., Mills et al. 2010) or as the spatial and temporal dimensions of a process or pattern, whereas governance literature often approaches scale by acknowledging the existence of various levels of social scale such as authorities, jurisdictions, decision making structures, and institutions (e.g., Hooghe and Marks 2003). In this literature, frequently using advanced methods and theories, scale challenges tend to be interpreted as only capturing ecological factors or social factors, respectively, in shaping temporal and spatial scales. To effectively embrace this multiplicity of approaches we define scale challenges as policy problems resulting from inappropriate consideration of scale aspects in any decision involved in biodiversity conservation.

\section{Frames of scale challenges}

Frame analysis starts from the acknowledgment of the existence of multiple interpretations in policy making, highlighting that unitary concepts or frames, as presented in dominant political discourses, contrast with a dynamic reality of multiple frames under conditions of multilevel governance (see also Verloo 2005). Frames guide people's interpretations and representations of reality, actions, and practices, and vice 
versa; they are often unconsciously adopted, used, and reconstructed in the course of communicative processes. Thus, framing denotes an active, processual phenomenon that implies agency and contention in dynamic reality construction and interpretation (Benford and Snow 2000). Therefore, the frame concept can help unravel the principles and assumptions underlying political debate and action (Forsyth 2003). In particular, Verloo (2005:20), building on Tuchman (1978) and Entman (1993), defines a policy frame as "an organizing principle that transforms fragmentary or incidental information into a structured and meaningful policy problem, in which a solution is implicitly or explicitly enclosed." In this paper, we define a frame as the organizing principle, or interpretation scheme that transforms multiple insights about scale problems and relevant solutions in the context of biodiversity conservation into a structured and meaningful scale challenge, e.g., the challenge of limited fit.

\section{METHODS}

\section{Research design and data collection}

Our study is based on frame analysis, a multidisciplinary social science research method exploring how people approach, understand, and discuss situations and activities (Goffman 1974). To investigate how scale challenges are framed in the context of conservation, we invited 58 stakeholders participating in biodiversity governance to eight focus group discussions in Finland and Greece between February 2011 and April 2011, four in each country. Each group had six to nine participants and met for three to four hours. The participants were selected through the "theoretical sampling" method (Strauss and Corbin 1998) and on the basis of our experiences from a stakeholder workshop held in September 2010 in the context of SCALES project (Paloniemi et al. 2012). We explored the findings from the first stakeholders focus group with two other groups, using different participants, to increase the trustworthiness of the findings. We also selected a focus group of experts in natural and social sciences, to allow empirical exploration of more theoretical scale issues and to guide us in analyzing and interpreting empirical data.

The research participants represented various governance levels, in different contexts, with the potential for conflicting opinions on biodiversity conservation. All groups were composed (Table 1) using identical criteria to ensure comparability of results between both the focus groups and the case study countries. Stakeholders came from several (i) administrative levels: local, regional, and national; (ii) institutions: public/private, market, civil society; (iii) hierarchies: senior officials/lead representatives, midlevel staff, and others; and (iv) participation levels: groups with a leading role and also groups not included in official decision making processes, but highly relevant, e.g., local community organizations and volunteers (see also Elbakidze et al. 2010, Kittinger et al. 2011). Before the groups met, a common introductory document, translated into Finnish and Greek, was sent to the participants, guiding them to discussion themes.

The discussion themes were categorized as (1) general scalerelated questions to explore understandings of the concept of scale and scale challenges and their relevance to biodiversity conservation, as well as (2) scale challenges of current policies and instruments driving the processes of designating and managing conservation areas, and (3) scale challenges related to the relationship of conservation areas to surrounding areas and to the integration of conservation with other policies, to discuss more specific scale-related problems and solutions. Some questions were formulated in the same way to all groups, whereas others were discussed differently in the scientists and stakeholders focus groups, to make the discussion relevant to people with different backgrounds. Within these general themes we explored both theoretical and practical topics regarding scale challenges (Appendix 2 presents the detailed structure of the discussions). In the focus groups, the themes were presented as open questions and arguments on PowerPoint slides (each question/argument on a different slide) to avoid misunderstandings and help participants focus on the discussion. Identical structures were followed in both countries to allow comparability of results.

The focus groups featured facilitation of participants' deliberative discussion and accordingly we paid attention to group dynamics by supporting argumentative interactions (Barbour and Kitzinger 1999). After presenting questions and arguments on slides, we encouraged different people to initiate discussion of each issue to ensure the democratic character of the discussions. All discussions were tape-recorded and transcribed.

\section{Data analysis}

As a first step of data analysis we defined a set of sensitizing questions comprising the dimensions of diagnosis of the policy problem (what is the scale problem represented to be), prognosis (solutions to this scale problem are proposed), and roles attributed to various actors in diagnosis and prognosis (see Snow and Benford 1992, Verloo 2005). This approach shares similarities to what Forsyth (2003:79) calls "problem closure." We further analyzed the above in terms of how scale and the relationship between ecological and governance scales are conceptualized. We related sensitizing questions to a set of more detailed questions. We formulated the detailed questions by drawing on insights from theory on scale challenges and scale concepts as described above and made sure these reflected the actual questions used during focus groups.

Subsequently, we scanned all transcripts for phrases indicating our set of questions and we gradually matched questions with all relevant quotes. Then, we coded the quotations around these questions as different frames of specific scale problems, e.g., limited understanding of the scale-dependence of diversity 
Table 1. Research participants in the focus group discussions in Finland and Greece.

\begin{tabular}{|c|c|}
\hline Stakeholders participating in biodiversity governance in Greece and Finland & Case study country \\
\hline $\begin{array}{l}\text { Ministry for the Environment, Energy and Climate Change } \\
\text { Ministry of Rural Development and Food } \\
\text { Ministry of the Environment } \\
\text { Ministry of Agriculture and Forestry } \\
\text { Committee Nature } 2000 \\
\text { National Land Survey of Finland } \\
\text { Finnish Forestry Development Centre Tapio } \\
\text { Geotechnical Chamber of Greece } \\
\text { Region of Attica } \\
\text { Region of Central Greece (Sterea Ellada) } \\
\text { Region of Central Macedonia } \\
\text { Forest district offices } \\
\text { Region of South-Western Finland } \\
\text { Municipalities (local administrative level) } \\
\text { Regional Forestry Agency } \\
\text { Regional environmental administrations }\end{array}$ & $\begin{array}{c}\text { GR } \\
\text { GR } \\
\text { FIN } \\
\text { FIN } \\
\text { GR } \\
\text { FIN } \\
\text { FIN } \\
\text { GR } \\
\text { GR } \\
\text { GR } \\
\text { GR } \\
\text { GR } \\
\text { FIN } \\
\text { GR \& FIN } \\
\text { FIN } \\
\text { FIN \& GR }\end{array}$ \\
\hline $\begin{array}{l}\text { National NGOs for nature conservation } \\
\text { Regional NGOs for nature conservation } \\
\text { Local NGOs for nature conservation } \\
\text { National NGO of forestry and agricultural producers } \\
\text { Regional NGO of forestry and agricultural producers } \\
\text { Local NGO conserving seminatural habitats }\end{array}$ & $\begin{array}{c}\text { GR \& FIN } \\
\text { GR \& FIN } \\
\text { GR \& FIN } \\
\text { FIN } \\
\text { FIN } \\
\text { FIN }\end{array}$ \\
\hline $\begin{array}{l}\qquad \text { Organizations with multilevel composition } \\
\text { Management agency for Koroneia and Volvi lakes } \\
\text { Management agency for Parnassos National Forest } \\
\text { Management agency for Parnitha National Forest } \\
\text { Forest and Park Service } \\
\text { Cooperation networks for conservation of forest biodiversity } \\
\quad \text { Other key, nonstate actors }\end{array}$ & $\begin{array}{l}\text { GR } \\
\text { GR } \\
\text { GR } \\
\text { FIN } \\
\text { FIN }\end{array}$ \\
\hline $\begin{array}{l}\text { Citizen networks } \\
\text { Organizations of volunteers } \\
\text { Finnish Museum of Natural History } \\
\text { Finnish Peatland Society }\end{array}$ & $\begin{array}{l}\text { GR \& FIN } \\
\text { GR \& FIN } \\
\text { FIN } \\
\text { FIN }\end{array}$ \\
\hline $\begin{array}{l}\text { Scientific community } \\
\text { Aristotle University of Thessaloniki (School of Biology, Department of Ecology) } \\
\text { University of the Aegean (Department of Environment) } \\
\text { National Center of Social Research (Institute of Urban and Rural Sociology) } \\
\text { Agricultural University of Athens (Department of Agricultural Economics and Rural Development) } \\
\text { Harokopio University (Department of Geography) } \\
\text { Forest Research Institute } \\
\text { University of Eastern Finland (Department of Geographical and Historical Studies) } \\
\text { University of Tampere (School of Management) } \\
\text { University of Helsinki (Departments of Biosciences, Social Research and Forest Sciences) } \\
\text { Finnish Environment Institute } \\
\text { Maj and Tor Nessling Foundation }\end{array}$ & $\begin{array}{l}\text { GR } \\
\text { GR } \\
\text { GR } \\
\text { GR } \\
\text { GR } \\
\text { GR } \\
\text { FIN } \\
\text { FIN } \\
\text { FIN } \\
\text { FIN } \\
\text { FIN } \\
29 \text { GR \& } 29 \text { FIN }\end{array}$ \\
\hline
\end{tabular}

components, and proposed solutions (see also van Lieshout et al. 2011). We used a coding scheme relating sensitizing and relevant detailed questions to codes emerging from data analysis. The criterion for judging when to stop adding data was based on the "theoretical saturation" of our analysis (Strauss and Corbin 1998). The analysis outcomes were discussed jointly over several meetings to minimize researcher bias (see also Sandbrook et al. 2010).

Because stakeholders do not share, a priori, the same interpretation scheme through which they frame scale challenges, we deliberately chose an open definition of scale challenges to give participants the freedom to define what they considered as the primary challenge in biodiversity conservation. This is consistent with a grounded theory approach (Strauss and Corbin 1998), and provides possibilities of capturing unexpected or distorted elements (Verloo 2005). This does not imply the absence of theoretical insights (see also Apostolopoulou and Pantis 2009, 2010, Apostolopoulou et al. 2012) but rather the use of theory to guide systematic and theoretically sensitive data analysis without prior 
imposition of a particular categorization of theoretical insights under specific frames. Thus, at the final stage of data analysis we reconstituted all emerged concepts by making connections between sensitizing questions, detailed questions, and codes to integrate the process through which scale challenges become articulated and amplified in a relatively unified and compelling form, through prioritizing, accenting, and emphasizing certain events, experiences, and beliefs over others. This analytical process, guided by participants' responses regarding the core scale challenge of conservation, eventually led to the emergence of three main frames. Finally, we recategorized all sensitizing and detailed questions and relevant codes under these three frames. The outcomes of data analysis are presented in Appendices 3, 4, 5, and Table 2, and the numbers of participants attributable to each frame in Table 3.

Frames are an appropriate theoretical notion and frame analysis a useful method for investigating the multiple interpretations inherent in policy making, nevertheless, frame categorization is a challenging and demanding analytical process. In our research, we tried to guide focus group discussions to encourage participants to prioritize what they consider as most important, most urgent, most relevant, etc. The importance of "forcing" respondents to focus their attention on issues crucial to their viewpoint has also been highlighted by Q methodology (e.g., Sandbrook et al. 2010). Focus groups were chosen as appropriate for the investigation of frames because encouraging people to discuss shared topics (Barbour and Kitzinger 1999) helps them to refine their arguments. However, inconsistencies or contradictory approaches within a frame are inevitable; to overcome this, and obtain an overall idea of the dominant interpretation schemes of participants, three researchers from Aristotle University of Thessaloniki participated in focus groups in Greece and three researchers from the Finnish Environment Institute in focus groups in Finland, taking detailed notes on the order of speakers, emphasis in their speech, and their nonverbal behavior.

\section{RESULTS}

\section{Different frames of scale challenges in biodiversity conservation in Finland and Greece}

The data analysis process led to the emergence of three different frames of scale challenges as derived from gaps in scientific knowledge (Frame 1), limited fit (Frame 2), and existing power relationships and learning processes (Frame $3)$. In Frame 1 the most urgent scale challenge relates to the limited incorporation of scientific knowledge regarding ecological scale into biodiversity conservation. Consequently its solution rests in conducting more research at different scales, obtaining more data, and incorporating new scalerelevant knowledge into policy. In Frame 2 the most urgent scale challenge relates to the nonalignment of natural and social scales and to mismatches between conservation areas and governance structures responsible for their management. In this frame, better institutional fit, support for multilevel arrangements, and optimization of the ideal governance level for dealing with each conservation problem at hand are prioritized as primary solutions to scale problems. In Frame 3 the most urgent scale challenge relates to the dominant idea of scale as a neutral, technical issue, discounting the fact that scale is "produced." This frame thus prioritizes the role played by existing unequal power relationships in scale configurations, as well as the deficiencies in current learning processes about the spatial patterning of the society-nature relationship, as the main causes of scale problems. This calls for investigations focused explicitly on how conservation scaling contributes to the production of new social-ecological entities in space and time. These differences have been reflected in the different scale problems and solutions that research participants prioritized as most significant (Appendices 3, 4, 5). Moreover, the three frames differed in how scales and the relationship between ecological and governance scales were portrayed (Table 2).

\section{Framing scale challenges as derived from gaps in scientific knowledge}

In this frame in both countries, natural scientists, stakeholders with key roles in nature administration, and park practitioners emphasized the importance of a better understanding and consideration of ecological phenomena's scale-dependence. They cited as characteristic examples the role of spatial and temporal scales in species richness, extinction rates, and distribution. Simultaneously, issues of interactions among species, representativeness, complementarity, and adaptation across scales were indicated as objective criteria in selecting and managing conservation areas: i.e., choosing its appropriate size, shape, and/or location or a suitable extent and grain for the studies needed in preparation of management plans and monitoring systems.

Participants focused on ecological scale as mainly involving species, habitats, and ecosystems, but emphasis on one or another of these organizational units (see also Hull et al. 2002) or on their interactions led to differing scale priorities. The same was evident regarding spatial scale; for example, ecologists participating in the experts focus groups argued that in a network of protected areas, where the focus lies "on the scale of the protected area," the core issues relate to its shape and size, whereas when it lies on "the wider geographic space," then the core issues relate to differences in species from one area to another, the need to connect species between the two areas, whether we need to design a corridor, etc.

Research participants supported the dominance of natural sciences in the processes of selecting a site and designing its boundaries and zoning plans and the use of standardized, rigorous, and objective methods whereas systematic 
Table 2. The outcomes of frame analysis regarding definitions of scales and of the relationship between ecological and governance scales.

\begin{tabular}{|c|c|c|c|}
\hline & Frame 1 & Frame 2 & Frame 3 \\
\hline \multirow[t]{6}{*}{ Definitions of scale } & $\begin{array}{l}\text { Dominance of uni-disciplinary } \\
\text { definitions and of theories and methods } \\
\text { mainly from natural sciences (GR: } 7 \text {; } \\
\text { FIN: 8) }\end{array}$ & $\begin{array}{l}\text { Multidisciplinary definitions by } \\
\text { combining theories of different } \\
\text { disciplines (GR: } 13 \text {; FIN: 12) }\end{array}$ & $\begin{array}{l}\text { Interdisciplinary definitions by } \\
\text { integrating theories and methods of } \\
\text { different disciplines (GR: 9; FIN: 9) }\end{array}$ \\
\hline & $\begin{array}{l}\text { Scale as the level of biological } \\
\text { organization (GR: } 7 \text {; FIN: } 8 \text { ) }\end{array}$ & $\begin{array}{l}\text { Scale as the level of biological } \\
\text { organization and as jurisdictional or/and } \\
\text { administrative levels (GR: } 13 \text {; FIN: } 12 \text { ) }\end{array}$ & $\begin{array}{l}\text { Coproduction of social and ecological } \\
\text { scales (GR: 9; FIN: 9) }\end{array}$ \\
\hline & $\begin{array}{l}\text { Scale as the extent and resolution of } \\
\text { data and study regions (GR: } 7 \text {; FIN: } 8 \text { ) }\end{array}$ & $\begin{array}{l}\text { Scale as the extent and resolution of } \\
\text { studies and of administrative regions } \\
\text { (GR: } 13 \text {; FIN: } 12 \text { ) }\end{array}$ & $\begin{array}{l}\text { Scale as encompassing both a } \\
\text { technical dimension and a social } \\
\text { construction (GR: } 4 \text {; FIN: } 6)\end{array}$ \\
\hline & $\begin{array}{l}\text { Scale as objective jurisdictional or/and } \\
\text { administrative levels (GR: 3; FIN: 5) }\end{array}$ & $\begin{array}{l}\text { Jurisdictional scale as the most } \\
\text { important scale - the problems and } \\
\text { solutions emerge there (GR: } 13 \text {; FIN: } \\
\text { 12) }\end{array}$ & $\begin{array}{l}\text { Administrative or/and jurisdictional } \\
\text { scale as geographically, historically } \\
\text { shaped (GR: } 9 ; \text { FIN: } 8 \text { ) }\end{array}$ \\
\hline & $\begin{array}{l}\text { Scale as a technical term or/and as } \\
\text { measurement (GR: 5; FIN: 5) }\end{array}$ & $\begin{array}{l}\text { Scale as distinct, hierarchically } \\
\text { organized levels (GR: 13; FIN: 12) }\end{array}$ & $\begin{array}{l}\text { Scale as coevolution of hierarchical } \\
\text { structures and occurring social- } \\
\text { ecological processes (GR: 6; FIN: } 8 \text { ) - }\end{array}$ \\
\hline & $\begin{array}{l}\text { Scale as a neutral, mainly scientific } \\
\text { term (GR: } 7 \text {; FIN: } 8 \text { ) }\end{array}$ & $\begin{array}{l}\text { Scale as having analytical fixity (GR: } \\
13 \text {; FIN: } 12 \text { ) }\end{array}$ & $\begin{array}{l}\text { Scale as a non neutral concept (GR: } 8 \text {; } \\
\text { FIN: } 8 \text { ) - Interactions within the } \\
\text { levels of a scale are dynamic (GR: } 6 \text {; } \\
\text { FIN: } 5 \text { ) }\end{array}$ \\
\hline \multirow{3}{*}{$\begin{array}{l}\text { Relationship between } \\
\text { ecological and governance } \\
\text { scales }\end{array}$} & No explicit links (GR: 7; FIN: 8) & Indirect links (GR: 13; FIN: 12) & Direct links (GR: 9; FIN: 9) \\
\hline & $\begin{array}{l}\text { Acknowledgment of interactions } \\
\text { between different levels of ecological } \\
\text { scale and between ecological, spatial } \\
\text { and temporal scales (GR: 7; FIN: 8) }\end{array}$ & $\begin{array}{l}\text { Acknowledgment of interactions across } \\
\text { various levels of ecological or } \\
\text { governance scales (GR: 13; FIN: 12) }\end{array}$ & $\begin{array}{l}\text { Acknowledgment of dialectical } \\
\text { interactions between and within } \\
\text { different scales (GR: 9; FIN: 8) - } \\
\text { Explicit references to cross-scale and } \\
\text { cross-level interactions (GR: 7; FIN: } \\
\text { 7) }\end{array}$ \\
\hline & $\begin{array}{l}\text { Social and natural scales are both } \\
\text { acknowledged as significant but not as } \\
\text { directly linked (GR: 7; FIN: } 6 \text { ) }\end{array}$ & $\begin{array}{l}\text { Biodiversity governance should find an } \\
\text { optimal solution to match conservation } \\
\text { efforts with human and ecological scales } \\
\text { (GR: } 13 \text {; FIN: } 12 \text { ) }\end{array}$ & $\begin{array}{l}\text { Active role of people in producing } \\
\text { geographical scales (GR: 7; FIN: 7) - } \\
\text { Scaling should reflect thoroughly } \\
\text { integrated social-ecological settings } \\
\text { (GR: } 7 \text {; FIN: } 6 \text { ) }\end{array}$ \\
\hline
\end{tabular}

conservation planning tools were framed as most relevant for achieving optimization of conservation scaling (Appendix 3). The latter were considered as necessary tools for determining the "correct" observational scale for studying the processes determining conservation targets as well as for defining optimal zoning within conservation areas. The following quote from an ecologist (focus group of experts, Greece) is indicative:

\section{For me, the core scale challenge of conservation is primarily exemplified by the scale-dependence of ecological processes and diversity components, and that's why I think that ecology has the primary role in conservation planning. ... I am referring to the stage before tracing the boundaries of a protected area, and during this stage we primarily need a biologist to decide which species, which ecosystem, should be protected and therefore which area.}

Research participants tended to define the role of governance as relating to choosing environmental administrations that base their decisions on scientific reasoning. Experts, namely, scientists and state officials, were portrayed as key actors, with the former having the leading role in applying the appropriate scientific methods and the latter in incorporating scientific knowledge about scale into policy. In this context, the recent decentralizing shifts in Greece and in Finland were perceived as related to scale challenges rather indirectly, by reconfiguring established relationships between environmental administrations, challenging previous expertise of employees. The composition of administrative boards was emphasized in terms of which scientific disciplines are represented and the role of funding for supporting scientifically based policy processes. As a representative of an environmental NGO (Finnish stakeholder focus group) argued:

We have a few more than 1800 Natura sites. Well, there is no need to make an Action Plan for Management [APM] for all of them. Many areas need just to be set aside, but, actually, we have in Finland this know-how concerning APMs ... Finland 
Table 3. The number of research participants that can be attributed to each frame. Frame 1 refers to framing scale challenges as derived from scientific knowledge gaps, Frame 2 refers to framing scale challenges as derived from limited fit, and Frame 3 refers to framing scale challenges as derived from existing power relationships and learning processes.

\begin{tabular}{|c|c|c|c|c|c|c|}
\hline & \multicolumn{2}{|c|}{ Stakeholders focus groups } & \multicolumn{2}{|c|}{ Experts focus groups } & \multicolumn{2}{|c|}{ Total } \\
\hline & Greece & Finland & Greece & Finland & Greece & Finland \\
\hline Frame 1 & 5 & 7 & 2 & 1 & 7 & 8 \\
\hline Frame 2 & 12 & 11 & 1 & 1 & 13 & 12 \\
\hline Frame 3 & 6 & 4 & 3 & 5 & 9 & 9 \\
\hline
\end{tabular}

has even brought the APM system of the Finnish Forest and Park Service to other countries. But the biggest problem seems to be that it's impossible to create them with the current [limited] funding.

Scale problems were also described as involving clarification of responsibilities and authorities between different governance levels, but, in contrast to Frame 2, such problems were considered as obstructing the adoption of scientifically sound policy and provision of the necessary information to stakeholders. Thus, the role of communities was framed as in need of being informed by science and policy. The following quotes from two representatives of NGOs (stakeholder focus groups) from Finland and Greece, respectively, are indicative:

Currently many people at local level, at countryside, do not support signs for gray areas of nature conservation at regional plans, meaning that they do not support that a bog should be signed reflecting that it cannot be dug away. They would support it, if they knew that the bog could be used, but not destroyed. But they don't know it, and there are strong interest groups opposing such practices at gray areas. ... It would be easier to combine the social and ecological aspects than it is, if we only would give scientific information thoroughly.

And:

We have serious knowledge gaps and limited environmental expertise in state administrations, especially at lower levels... I see it in everyday issues that knowledge of basic conservation subjects is missing. And we, NGOs, often have to fill these gaps and inform not only state entities and local government but also people about the importance of designing sites which do not "fragment" biodiversity patterns.

Overall, scale was conceptualized mainly in line with ecological literature and it was considered as the most relevant scale for biodiversity conservation. Moreover, participants argued that economic or social factors could not have a primary position in conservation scaling by framing it as a purely scientific task.
A significant difference between countries was that in Greece the criticism was mainly targeted at the absence of qualified experts and the limited adoption of scale relevant methods. However, in Finland, the limited influence of experts on current conservation scaling caused concern (Appendix 3).

\section{Framing scale challenges as derived from limited fit}

In this frame an often-mentioned scale problem affecting both site selection and management was that the spatial and temporal scales of management and the scales of ecosystem functioning do not coincide either temporally or spatially (see Appendix 4), coupled with the fact that management institutions responsible for the conservation objective and the conservation objective itself do not refer to the same geographical area. It was argued that the latter is even more evident in the case of migratory species and transboundary conservation issues, given that they require interstate cooperation to align different national policies across time and space. Overall, coordination issues and processes of governance rescaling were directly related to the resolution (or not) of issues of limited fit, as the following quote from a representative of regional administration (stakeholder focus group, Greece) indicates:

The new municipality which resulted from Kallikratis administration reform does not cover the catchment area of Koroneia Lake. Responsible authorities are diffused at different jurisdictional and administrative levels and the latter do not refer to the same spatial area as the protected lake... So when we will try to implement the management plan at the level of catchment area a variety of fit problems will probably emerge.

Conservation policies were criticized for following current administrative borders, mainly on the grounds that these often differ from the borders of natural resources (see Appendix 4). Water Framework Directive was often mentioned in Greek focus groups as a good example of a spatially "sensitive" policy because it is explicit about the boundaries of its subject (water basins) in contrast to the Natura 2000 network in which a similar approach was not adopted for designing sites. Research participants also proposed that policy instruments should "match" the spatial differentiation that drivers causing biodiversity loss, e.g., wetland loss or fragmentation of forest 
habitats, show across administrative levels. Discussions were also dominated by bureaucratic complexities and administrative divisions of natural resources, reflected in agendas or departmental divisions in ministries and administrations differing from natural borders. As a representative of the Finnish Ministry of the Environment (stakeholder focus group) argued:

... We have Natura sites that should be actively managed and used, but that are not managed by Finnish Forest and Park Service. In addition, these sites cover rather larger areas. We have, for example, forest habitats on eskers, complete lines of eskers, large areas altogether. There the vegetation sets special demands for the forestry practices. During the latest negotiation round of rural aid, we suggested that we could use EU-subsidies for these areas in order to modify forestry practices at least on the Natura sites. However, we were informed that in Finland there is a strict dividing line between fields and forests, so...

... It's the border ditch! [laughing]

... So it's impossible. But perhaps during the next round.

Proposals for increasing the size of conservation areas were also frequent, and in these participants tended to draw mechanistic boundaries between the conservation object and the surrounding area reflecting a spatial scale frame divided between "protected" and "unprotected." As a representative of local government (stakeholder focus group, Greece) put it:

... In our area the anthropogenic factor influences the ecosystem and thus also the protected area. There were fish populations that have now disappeared from the catchment area because of these uncontrolled human actions and this shows the future: that they will also disappear from the [protected] ecosystem itself.

The ability to deal effectively with the separation of administrative levels into vertical and horizontal nested hierarchies was emphasized. An optimal solution was to "match" various hierarchical governance structures with each other to ensure coherent conservation networks. It was argued that this could be achieved, for example, by combining local and regional governing structures, by encouraging practices maintaining or supporting biodiversity, and by educating people to change their behavior to scale up (or down) the governance levels, e.g., moving horses from the capital region to rural areas to graze on meadows during summer when the cities' riding schools are closed. Overall designing new instruments, such as planning, zoning, integrated regulatory domains, or economic incentives at the level of conservation objectives as well as the alignment of responsible authorities, borders of administration, protected areas, management, and participatory institutions to the same spatial area were framed as solutions to scale problems. In such proposals, discussions were dominated by disagreements on which governance level would be optimal for matching ecological and social scales (see Appendix 4).

Issues of justice and power were related more explicitly to scale challenges than in Frame 1 and were attributed to the top-down character of most policies and governance mechanisms. Several issues emerged from this as the question of which level is the most relevant for applying sanctions, for deciding on the allocation of funds, for receiving incentives and subsidies according to conservation costs, or for being responsible for policies whereas scientists and authorities of all levels as well as NGOs, landowners, and the business sector were portrayed as actors who should be included in biodiversity governance.

Though stakeholders acknowledged the need to address both ecological and governance scales, they tended to frame them in line with their educational or professional background by portraying scale as either the temporal and spatial scale relevant for ecological phenomena, or as the administrative and jurisdictional scale relevant for social phenomena. This underlined the difficulties in approaching scale in an interdisciplinary manner; governance scale was seen as something "imposed" on ecological scale as the following quotes from representatives of regional environmental authorities (stakeholder focus groups) in Greece and in Finland, respectively, show:

Beside the spatial and temporal scales which are inherent to ecosystems all other scales are anthropogenic. The scale challenge will emerge and become obvious in jurisdictional or governance scale and in state inability to align it appropriately with forests, rivers, wetlands etc.

And:

The scales come mostly from the administration and that's why contradictions arise, but then we, our education [based on natural sciences] is of that type that it could give opportunities to take into account the whole scale of biodiversity.

This frame was dominant in both countries (Table 3 ) and even though emphasis was given to scale challenges related to biodiversity conservation both within and outside strictly protected areas, in Greece the frame reflected a criticism of the absence of such integrative policies, but in Finland, of the weaknesses of existing policies.

Framing scale challenges as derived from existing power relationships and learning processes

In this frame conservation areas were framed as socialecological spatial entities contributing to the production of space; issues related to boundaries and zoning plans were 
framed as major scale problems by criticizing the very notions of "boundary" and "zone." Participants argued that conservation expansion, i.e., establishing networks of conservation areas, and increasing regulations and sanctions restricting human activities affecting species, habitats, and ecosystems, results in significant areas of landscape with human presence as territories of conservation (see also Zimmerer 2000). Conservation scaling, by regulating access and control over natural resources, was framed as contributing to the production of new social-ecological assemblages with distinct, albeit dynamic, characteristics in space and time, and was criticized for neglecting that "borders" are dynamic entities, simultaneously natural and social. As a geographer (experts focus group, Greece) argued:

For me it is an absurd idea to talk about governance
and ecological scales ... For example, the fact that
the Water Framework Directive focuses on the
watershed is crucialnotonly for the wetland but also
for people: the watershed is the number-one
anthropogeographical conditionfor life in a specific
area... And the same could be said for Natura 2000
sites: the point is not only who decides where nature
stops and society starts but the very fact that this
question about "natural" borders is being posed a
priori in dominant scientific discourses as a
legitimate question.

Simultaneously, from the standpoint of complex cross-scale dynamics, the need to approach all relevant levels influencing each other was expressed (see also Buizer et al. 2011). Participants argued that the dominant division of space through conservation scaling assists the statistical collection of data but is often unrelated to everyday life. It was argued that a local community issue is never just a local conservation issue and vice-versa, but these are inherently intertwined with factors and processes on several scales, something largely ignored by setting zones and boundaries arbitrarily restricting human practices within geographically fixed areas (see also Zimmerer 2000). Examples were cited where area designation caused fragmentation of the cross-scale pattern of local land use practices, depriving people of resources vital to their subsistence, as in Parnitha Natura 2000 site and National Forest (Greece) where people have been deprived of both livestock resources and firewood since the designation of the park. As an agriculturist from the Greek experts focus group argued, conservation scaling, by excluding spaces from social life, "conserves" them as "museums," destroying the "function" of this space because "it wasn't a museum, it was something else, a part of the social life of people interacting with this place."

It was also argued that concepts of multiple equilibria, dynamic nature of ecosystems, thresholds, and "flux of nature" must be integrated into current static conceptualizations of ecological scale and guide conservation scaling. The Greek stakeholder focus group proposed replacing the dominant conservation approach, i.e., restrictions on land use within the boundaries of the protected lake ecosystem under discussion (Koroneia Lake), with a more dynamic one. This would continuously monitor all activities throughout the catchment area, create databases, utilizing both authorities and individuals to record how temporal and spatial variations in the lake ecosystem (the lake faces serious problems of drainage) affect fishing, agricultural activities, and fish and bird populations, targeting increasing local communities' capacity to learn to recognize and respond to socialenvironmental changes.

Similarly, in the Finnish stakeholder focus group, emphasis on processes operating simultaneously on several spatial levels was combined with calls for shifting conservation focus to overall land management. There were proposals to replace compensation-based policies, restricted to protected areas, by supporting production related incentives, in conjunction with learning on diversified usages of natural resources. Participants felt that management of conservation areas cannot be effective without attention to activities, policies, and areas affecting them, otherwise conservation professionals would choose an observational scale that de facto excludes factors explaining the operational scales under examination, leading to a focus on smaller and smaller land parcels divorced from real processes and structures. Therefore selection of observational scales was framed as a complex social and scientific issue with non-neutral implications for scientific explanations, as has been seen in both countries when conservation planning has been driven by available data on particular scales (e.g., Natura 2000 databases) ignoring, because of their absence from databases, the scaling of drivers causing biodiversity loss, and the spatial patterning of local practices and natural resources.

Multilevel governance was perceived as a process whereby decision making levels and jurisdictional boundaries, as well as the relations between them, are formed and reshaped both by dynamic power relations and by the coproduction of social and natural scales. Participants of the Finnish experts focus group emphasized that actors for participatory processes are often selected from particular perspectives, focusing on a specific spatial or administrative level, ignoring both the remit and influence of the agency beyond a specific conservation area, and the links between local communities and such agencies, e.g., market forces, according to the power relations within them. Overall, changes in geographic boundaries or in the strictness of regulations within conservation zones were framed as reflecting outcomes of scalar politics altering and altered by socio-spatial dynamics. The conflicts during establishment of Natura 2000, e.g., hunger strikes in Finland, were cited as characteristic examples of these problems, the role of the EU being emphasized. As a social scientist (Greece) put it: 
Local communities experienced European directives as something imposed from the outside and conservation initiatives as actions from a "space" which functions and exists outside and independently of them but which at the same time changes the balances in "their" space. ... Habitats directive is a good example for such "scale" enforcements because it was designed "in vitro" without considering national geographical, historical, social particularities but rather European priorities.

Ignorance of the consequences of the spatio-temporal distribution of conservation policies costs and benefits was criticized (see Appendix 5) and current conservation planning was portrayed as a bureaucratic-scientific endeavor (see also Schultz et al. 2007) supporting the predominance of natural science and scientists in conservation scaling. Ecological connectivity was argued to necessitate social connectivity because the former requires a wider agreement in a socialecological sustainable direction. Participants explicitly supported socially inclusive conservation with active citizen involvement and learning processes through schools, universities, etc. on how people interact with ecosystems and what form this interaction should take, e.g., how a biotope could be near an organic farm or an ecological corridor bringing eco-tourism resources at the same time. Cross disciplinary links were considered as enabling the reanalysis of the temporal and spatial scales at which social-ecological systems interact. However, the Finnish experts focus group considered such interdisciplinary activities as challenging because "scales do change all the time, and the borders are evolving, but people and decision makers have a tendency to stabilize them" by thinking certain scales are "natural," linear, and neutral (Appendix 5).

In this frame, the aim of thoroughly understanding the interrelationships between ecological and governance scales was evident. The following quote from a critical discussion on the visual presentation of social-ecological systems (see Ostrom 2009) in the Finnish experts focus group is indicative:

If we take a look on the Ostrom's scheme ... the famous figure of social-ecological system, it is interesting that those globes having interaction are either social or ecological ones. For me they pose an intellectual challenge: "well wasn't the idea that they are integrated?" Meaning that the globes should be entities integrated inside each other, in that sense that you are a social and ecological organism and you are, here [draws], one whole. There are no two ones. I find this as an intellectual challenge - that future research should draw a model, in which there are no governance and users here and ecosystems and things like it there, but an entity integrating them.

\section{DISCUSSION}

The three frames reflect different organizing principles and interpretation schemes through which scale challenges are approached, scale problems and solutions are prioritized, together with differing understandings of the concept of scale and of the relationship between social and ecological scales. Therefore, transition to scale-sensitive biodiversity governance, as defined in this paper, requires acknowledgement that involved stakeholders do not share a priori the same understanding of the problem under discussion (Adams et al. 2003).

In particular, framing scale challenges as mainly derived from gaps in scientific knowledge about ecological processes at different scales reflects a tendency to depoliticize scale challenges both by conceptualizing scale as a neutral scientific term and by presenting scale problems as facts not subject to different opinions and ideologies (see also Verloo 2005). This often reflected a positivist epistemological approach; conservation science and policy were approached as distinct discourses and real politics were framed as disrupting the accuracy and objectivity of natural science, especially conservation biology knowledge, framing the latter as most relevant for achieving optimal conservation scaling. Scale challenges were often delimited to issues of precise measurements of biodiversity components, optimal designation of boundaries and zoning plans, all of which, in turn, were considered based on objective tools and data, reducing scale problems to "purely technical matters" (Harvey 1996:203). More than in Frame 2, the concept of scale was understood as "size" (Sayre 2008), i.e., measurements in terms of standardized units (Rykiel 1998, as cited in Sayre 2008).

Framing scale challenges as mainly derived from limited fit, in contrast to Frame 1, relates the causes underlying scale challenges mainly to governance and not to scientific reasons (see also Crowder et al. 2006). By framing scale in terms of distinct, hierarchically, and linearly organized levels, this frame shares, more frequently than Frame 1, similarities with an understanding of scale as "level" (Sayre 2008). However, even though conservation areas were framed as encompassing social and ecological scales, mismatches between biodiversity objectives and human action were often framed rather linearly by portraying ecological and social (seen as governance levels) scales as preordained by nature or history, having analytical fixity and more or less stable boundaries within which conservation policy should find the right "match." Thus, there were often difficulties in understanding the dynamics between and within scales reflecting an underestimation of the fact that conservation "politics at or about a given scale are inseparable from politics concerning relationships among scales" (McCarthy 2005:738; emphasis in original). In other cases, sharp distinctions between horizontal and vertical governance interplay were adopted by considering the scale challenge as most evident in the case of vertical interplay as the emphasis 
on different administrative levels showed (Termeer et al. 2010).

In both these frames, stakeholders had difficulty in analyzing dynamic outcomes of cross-scale interactions, reflecting in Frame 1 an understanding of conservation areas as more or less "agency-free" (Jones 2009) and in Frame 2, an inability to discuss that interests or policies driving biodiversity loss do not align closely with particular natural borders or with governance and administrative levels (Lebel et al. 2005). Underestimating the extent to which people are part of the production of geographical scales made it difficult to approach biodiversity components (nature) and livelihoods related to them (society) as simultaneously altering and coconstructing each other (Bryan 2012) in space and time. This potentially obstructs transitions to scale-sensitive biodiversity governance by reproducing an ontological separation between ecological and social scales.

However, in framing scale challenges as derived mainly from existing power relationships and learning processes, by emphasizing processes and their interactions, the concept of interrelationship proved crucial (Sayre 2005). In contrast to the previous frames, the causes underlying the emergence of scale challenges were directly related to how ecological and social scale configurations are influenced by dominant conservation scaling and biodiversity governance arrangements. The evolution of these was approached as inscribing boundaries on the landscape, thus highlighting the relevance of power relations for ecological scales as the outcomes of these arrangements change the human-environment relationship in a spatially defined way, creating new spatial configurations of socio-environmental dynamics (Turner 2006, Swyngedouw 2007, Neumann 2009). Scales were not framed as socially or politically neutral but, rather, as embodying and expressing power relationships (Swyngedouw 1997, Görg 2007), whereas the presumptions about the "natural" geographical units that shape the organization of governance were framed as not meaningful (Harvey 1995). Boundaries and zoning plans were considered as possible ways to enforce a dual widening schism, the first between degraded areas that deserve to "be sacrificed" and those earmarked for survival (see also Fabiani 1985, Zimmerer 2000) and the second between biodiversity objectives and people. However, opinions differed regarding the ontological base of scale, and whereas some participants emphasized constructivist approaches (c.f., Marston 2000, Marston et al. 2005), others were more critical toward the fact that overemphasis on relativism or subjectivism could possibly obscure the material basis of scales. This reflects the different understandings of the relationship between epistemological and ontological moments of scale (Sayre 2005, 2008, Manson 2008) existing not only between but also within different frames.
Despite acknowledgement by all stakeholders of the importance of considering economic, social, political, and ecological factors in designing and managing conservation areas, considerable differences appeared in how these issues were related to scale challenges. Moreover, even though on some occasions there was consensus on specific scale problems, e.g., limited understanding of the scale-dependence of ecological phenomena, there were considerable differences regarding the scale problem having high priority. Thus, it became evident that stakeholders' frames are much more mixed than those described theoretically, and strict divisions between them or a priori categorizations can hide the complex reality of policy debates. It is indicative that although the three frames relate to the challenges presented by Cash et al. (2006), they also transcend them. For example, in Frame 3, ignorance was mostly related to the fact that current scale-related research does not focus on the patterning of socio-natures, whereas in Frame 1 ignorance mostly related to limited data on biodiversity patterns across scales. On the other hand, both Frames 2 and 3 approached the social aspect as internal to scale-related scientific knowledge and conservation scaling; social relations with nature and local knowledge were considered to have a position informing science and policy. Similarly, Cash et al.'s (2006) challenges are based on a specific interdisciplinary definition of scale whereas in our three frames different dominant definitions of scales are reflected in each frame.

Overall, our results reflected the notion that scale is a concept with different meanings across scientific disciplines or fields of professional expertise, whereas monodisciplinary approaches exhibited enduring strength. Significantly, in both countries, even though when asked directly, stakeholders felt less able than scientists to discuss scale challenges in more theoretical terms; when the research themes posed by the authors were discussed deliberatively, they actively participated in scale-framing based on their context-specific experiences. The latter confirms that scale issues are present in everyday life (McCarthy 2005) as well as in policy and governance decisions even when not addressed or recognized as such.

Despite differences in emphasis (as shown in Appendices 3, 4 , 5) between the two countries, reflecting the current discourses of biodiversity conservation at the national level, interestingly, we found that variations between frames, as well as within the same frame, were greater in Frames 1 and 2. This probably stems from Frame 3 presenting a more substantial critique of conservation scaling currently being driven by systematic conservation planning, and largely reproducing a dichotomy between social and ecological scales (see also Adams and Hutton 2007). Similarly, Frame 3 reflected a critique of dominant conservation ideologies, strongly shaped 
in both countries by common EU conservation policies, such as Natura 2000, neoliberalization processes, and by the shared cultural background dominated by several centuries of Western scientific traditions.

To understand the role of different frames in either promoting or hindering transitions to scale-sensitive biodiversity governance, these should be discussed with a shift of biodiversity politics to more deliberative governance modes open to wider public participation in biodiversity projects, laws, and policies (Lebel et al. 2006, Paloniemi and Tikka 2008, Paloniemi and Varho 2009). Deliberative discussions could include choices of observational and operational scales, zoning plans, and monitoring systems, along with moving delineation of boundaries, often based on inclusions and exclusions or linear understandings of humans, conservation objects, and the spatial-temporal patterning of their relationship, toward multiscaled analyses connected to geographies of livelihoods (Turner 2006). To foster this, the focus could be shifted toward considering community territories in which people live and work as multifaceted and networked conservation areas and thus "these people, their homes, and their livelihood habitats would compose a conservation territory that is centered on them and their activities rather than on select patternings of rare plant or animal species" (Zimmerer 2000:360). Possible concrete arenas for such learning also appeared in the focus-group discussions.

\section{CONCLUSION}

Analyzing different frames of scale challenges proved not only an empirical challenge but also a fundamental conceptual challenge (Sayre 2008) for the understanding of society-nature interactions (Haila and Levins 1992). Frame emphasizing the role of knowledge reflected a scientific optimism that better understanding of the scale-dependence of ecological phenomena and the multiscale nature of biodiversity will resolve the scale challenges of conservation area designation and management. Frame emphasizing the issue of fit underlined the positive role of matching instruments to the scale dependence of drivers of biodiversity loss and aligning interests, stakeholders, and natural resources borders in space and time through governance structures. Frame emphasizing learning and power aspects calls for more fundamental steps toward scale-sensitive biodiversity governance, because it placed the redesigning of conservation policies at the core of solutions for scale challenges by approaching conservation areas as social-ecological spatial entities and, by promoting learning, on the production of, and interaction between, natural and social scales.

The temporal and spatial scales at which humans operate as ecological agents are constantly changing (Harvey 1993) producing new forms of territorial organization that "interact and intertwine to territorialize capital upon each geographical scale" (Brenner 1998:464). Achieving a shift toward "scalesensitive" environmental governance seems to require moving beyond the classical positivist scientific approaches or "onesize-fits-all" governance processes of biodiversity conservation that treat natural and social scales as ontologically distinct and stable. Unraveling cross-scale interactions, overcoming scale challenges through learning, and obtaining the capacity to "arbitrate and translate between" the different scales yielded by various projects (Harvey 1993:47) would be crucial for resolving the contradictions in the spatial patterning of humannature relationship that current conservation scaling often produces. A dialogue between the aspects of different frames could contribute toward the above direction.

Responses to this article can be read online at: http://www.ecologyandsociety.org/issues/responses. $\mathrm{php} / 5181$

\section{Acknowledgments:}

Funding for this research has been provided by the LargeScale Integrating Project within FP7, SCALES (Grant 226 852). We thank the many people and organizations involved for providing us with information necessary for our research and, most of all, for participating in the focus groups' discussions in Greece and Finland. The language of this paper was improved vastly by Jonathan Smith. Finally, we thank two anonymous reviewers as well as the editors for their very constructive suggestions.

\section{LITERATURE CITED}

Adams, W. M., D. Brockington, J. Dyson, and V. Bhaskar. 2003. Managing tragedies: understanding conflict over common pool resources. Science 302:1915-1916.

Adams, W. M., and J. Hutton. 2007. People, parks and poverty: political ecology and biodiversity conservation. Conservation and Society 5:147-183.

Apostolopoulou, E., E. Drakou, and J. D. Pantis. 2012. Unraveling stakeholders' discourses regarding sustainable development and biodiversity conservation in Greece. Pages 405-430 in C. Ghenai, editor. Sustainable development policy and urban development - tourism, life science, management and environment. InTech Publications, Rijeka, Croatia. http://dx.doi.org/10.5772/26942

Apostolopoulou, E., and J. D. Pantis. 2009. Conceptual gaps in the national strategy for the implementation of the European Natura 2000 conservation policy in Greece. Biological Conservation 142:221-237. http://dx.doi.org/10.1016/j.

biocon.2008.10.021 
Apostolopoulou, E., and J. D. Pantis. 2010. Development plans versus conservation: explanation of emergent conflicts and state political handling. Environment and Planning $A$ 42:982-1000. http://dx.doi.org/10.1068/a42163

Baker, M., S. Hincks, and G. Sherriff. 2010. Getting involved in plan making: participation and stakeholder involvement in local and regional spatial strategies in England. Environment and Planning C: Government and Policy 28:574-594. http:// dx.doi.org/10.1068/c0972

Barbour, R. S., and J. Kitzinger, editors. 1999. Developing focus group research: politics, theory and practice. Sage, London, UK. http://dx.doi.org/10.4135/9781849208857.n14

Benford, R. D., and D. A. Snow. 2000. Framing processes and social movements: an overview and assessment. Annual Review of Sociology 26:611-639. http://dx.doi.org/10.1146/ annurev.soc.26.1.611

Boykoff, M. T., D. Frame, and S. Randalls. 2010. Discursive stability meets climate instability: a critical exploration of the concept of "climate stabilization" in contemporary climate policy. Global Environmental Change 20:53-64. http://dx.doi. org/10.1016/j.gloenvcha.2009.09.003

Brenner, N. 1998. Between fixity and motion: accumulation, territorial organization, and the historical geography of spatial scales. Environment and Planning D: Society and Space 16:459-481. http://dx.doi.org/10.1068/d160459

Brenner, N. 2001. The limits to scale? Methodological reflections on scalar structuration. Progress in Human Geography 25:591-614. http://dx.doi.org/10.1191/03091320$\underline{1682688959}$

Bryan, S. 2012. Contested boundaries, contested places: the Natura 2000 network in Ireland. Journal of Rural Studies 28:80-94. http://dx.doi.org/10.1016/j.jrurstud.2011.09.002

Buizer, M., B. Arts, and K. Kok. 2011. Governance, scale, and the environment: the importance of recognizing knowledge claims in transdisciplinary arenas. Ecology and Society 16(1): 21. [online] URL: http://www.ecologyandsociety.org/vol16/ $\underline{\text { iss } 1 / \operatorname{art} 21 /}$

Cash, D. W., W. Adger, F. Berkes, P. Garden, L. Lebel, P. Olsson, L. Pritchard, and O. Young. 2006. Scale and crossscale dynamics: governance and information in a multilevel world. Ecology and Society 11(2): 8. [online] URL: http:// www.ecologyandsociety.org/vol11/iss2/art8/

Collins, S. L., S. R. Carpenter, S. M. Swinton, D. E. Orenstein, D. L. Childers, T. L. Gragson, N. B. Grimm, J. M. Grove, S. L. Harlan, J. P. Kaye, A. K. Knapp, G. P. Kofinas, J. J. Magnuson, W. H. McDowell, J. M. Melack, L. A. Ogden, G. P. Robertson, M. D. Smith, and A. C. Whitmer. 2011. An integrated conceptual framework for long-term social- ecological research. Frontiers in Ecology and the Environment 9:351-357. http://dx.doi.org/10.1890/100068

Crowder, L. B., G. Osherenko, O. R. Young, S. Airamé, E. A. Norse, N. Baron, J. C. Day, F. Douvere, C. N. Ehler, B. S. Halpern, S. J. Langdon, K. L. McLeod, J. C. Ogden, R. E. Peach, A. A. Rosenberg, and J. A. Wilson. 2006. Resolving mismatches in U.S. ocean governance. Science 313:617-618. http://dx.doi.org/10.1126/science.1129706

Cumming, G. S., D. H. M. Cumming, and C. L. Redman. 2006. Scale mismatches in social-ecological systems: causes, consequences, and solutions. Ecology and Society 11(1): 14. [online] URL: http://www.ecologyandsociety.org/vol11/iss1/ art14l

Ekstrom, J. A., and O. R. Young. 2009. Evaluating functional fit between a set of institutions and an ecosystem. Ecology and Society 14(2): 16. [online] URL: http://www.ecologyandsociety. org/vol14/iss2/art16/

Elbakidze, M., P. K. Angelstam, C. Sandström, and R. Axelsson. 2010. Multi-stakeholder collaboration in Russian and Swedish model forest initiatives: adaptive governance toward sustainable forest management? Ecology and Society 15(2): 14. [online] URL: http://www.ecologyandsociety.org/ vol15/iss $2 /$ art14/

Entman, R. M. 1993. Framing: toward clarification of a fractured paradigm. Journal of Communication 43:51-58. http://dx.doi.org/10.1111/j.1460-2466.1993.tb01304.x

Fabiani, J. L. 1985. Sciences des écosystèmes et protection de la nature. Pages 75-93 in A. Cadoret, editor. Protection de la nature. Histoire et idéologie. L' Harmattan, Paris, France.

Folke, C., L. Pritchard, F. Berkes, J. Colding, and U. Svedin. 2007. The problem of fit between ecosystems and institutions: ten years later. Ecology and Society 12(1): 30. [online] URL: http://www.ecologyandsociety.org/vol12/iss1/art30/

Forsyth, T., editor. 2003. Critical political ecology: the politics of environmental science. Routledge, London, UK.

Gabriel, D., S. M. Sait, J. A. Hodgson, U. Schmutz, W. E. Kunin, and T. G. Benton. 2010. Scale matters: the impact of organic farming on biodiversity at different spatial scales. Ecology Letters 13:858-869. http://dx.doi.org/10.1111/ j.1461-0248.2010.01481.x

Gibson, C. C., E. Ostrom, and T. K. Ahn. 2000. The concept of scale and the human dimensions of global change: a survey. Ecological Economics 32:217-239. http://dx.doi.org/10.1016/ S0921-8009(99)00092-0

Goffman, E., editor. 1974. Frame analysis: an essay on the organization of experience. Harvard University Press, Cambridge, UK. 
Görg, C. 2007. Landscape governance: the "politics of scale" and the "natural" conditions of places. Geoforum 38:954-966. http://dx.doi.org/10.1016/i.geoforum.2007.01.004

Haila, Y., and R. Levins, editors. 1992. Humanity and nature: ecology, science and society. Pluto Press, London, UK.

Harvey, D. 1993. The nature of environment: the dialectics of social and environmental change. Socialist Register 29:1-51.

Harvey, D. 1995. Globalisation in question. Rethinking Marxism 8:1-17. http://dx.doi.org/10.1080/08935699508685463

Harvey, D., editor. 1996. Justice, nature and the geography of difference. Blackwell Publishers, Malden, Massachusetts, USA.

Hooghe, L., and G. Marks. 2003. Unraveling the central state, but how? Types of multi-level governance. American Political Science Review 97:233-243.

Hull, R. B., D. P. Robertson, D. Richert, E. Seekamp, and G. J. Buhyoff. 2002. Assumptions about ecological scale and nature knowing best hiding in environmental decisions. Conservation Ecology 6(2): 12. [online] URL: http://www. consecol.org/vol6/iss $2 /$ art 12

Jones, M. 2009. Phase space: geography, relational thinking, and beyond. Progress in Human Geography 33:487-506. http://dx.doi.org/10.1177/0309132508101599

Kittinger, J. N., A. Dowling, A. R. Purves, N. A. Milne, and P. Olsson. 2011. Marine protected areas, multiple-agency management, and monumental surprise in the northwestern Hawaiian islands. Journal of Marine Biology Article ID 241374. http://dx.doi.org/10.1155/2011/241374

Kok, K., and T. A. Veldkamp. 2011. Scale and governance: conceptual considerations and practical implications. Ecology and Society 16(2): 23. [online] URL: http://www. ecologyandsociety.org/vol16/iss2/art23/

Lebel, L., J. M. Anderies, B. Campbell, C. Folke, S. HatfieldDodds, T. P. Hughes, and J. Wilson. 2006. Governance and the capacity to manage resilience in regional social-ecological systems. Ecology and Society 11(1): 19. [online] URL: http:// www.ecologyandsociety.org/vol11/iss 1/art19/

Lebel, L., P. Garden, and M. Imamura. 2005. The politics of scale, position, and place in the governance of water resources in the Mekong region. Ecology and Society 10(2): 18. [online] URL: http://www.ecologyandsociety.org/vol10/iss2/art18/

Levin, S. A. 1992. The problem of pattern and scale in ecology. Ecology 73:1943-1967. http://dx.doi.org/10.2307/1941447

Manson, S. M. 2008. Does scale exist? An epistemological scale continuum for complex human-environment systems. Geoforum 39:776-788. http://dx.doi.org/10.1016/j.

geoforum.2006.09.010
Marston, S. A. 2000. The social construction of scale. Progress in Human Geography 24:219-242. http://dx.doi. org/10.1191/030913200674086272

Marston, S. A., J. P. Jones, III, and K. Woodward. 2005. Human geography without scale. Transactions of the Institute of British Geographers 30:416-432. http://dx.doi. org/10.1111/j.1475-5661.2005.00180.x

McCann, E. J. 2003. Framing space and time in the city: urban policy and the politics of spatial and temporal scale. Journal of Urban Affairs 25:159-178. http://dx.doi.org/10.1111/1467-9906. $\underline{\mathrm{t} 01-1-00004}$

McCarthy, J. 2005. Scale, sovereignty, and strategy in environmental governance. Antipode 37:731-753. http://dx. doi.org/10.1111/j.0066-4812.2005.00523.x

Millennium Ecosystem Assessment (MEA). 2005. Ecosystems and human well-being. Island Press, Washington, D.C., USA.

Mills, M., R. L. Pressey, R. Weeks, S. Foale, and N. C. Ban. 2010. A mismatch of scales: challenges in planning for implementation of marine protected areas in the Coral Triangle. Conservation Letters 3:291-303. http://dx.doi. org/10.1111/j.1755-263X.2010.00134.X

Neumann, R. P. 2009. Political ecology: theorizing scale. Progress in Human Geography 33:398-406. http://dx.doi. org/10.1177/0309132508096353

Ogunseitan, O. A. 2003. Framing environmental change in Africa: cross-scale institutional constraints on progressing from rhetoric to action against vulnerability. Global Environmental Change 13:101-111. http://dx.doi.org/10.1016/ S0959-3780(03)00004-9

Ostrom, E. 2009. A general framework for analyzing sustainability of social-ecological systems. Science 325:419-422. http://dx.doi.org/10.1126/science.1172133

Paloniemi, R., E. Apostolopoulou, E. Primmer, M. Grodzinska-Jurczak, K. Henle, I. Ring, M. Kettunen, J. Tzanopoulos, S. G. Potts, S. van den Hove, P. Marty, A. McConville, and J. Similä. 2012. Biodiversity conservation across scales: lessons from a science-policy dialogue. Nature Conservation 2:7-19. http://dx.doi.org/10.3897/

natureconservation.2.3144

Paloniemi, R., and P. M. Tikka. 2008. Ecological and social aspects of biodiversity conservation on private lands. Environmental Science \& Policy 11:336-346. http://dx.doi. org/10.1016/j.envsci.2007.11.001

Paloniemi, R., and V. Varho. 2009. Changing ecological and cultural states and preferences of nature conservation policy: the case of nature values trade in south-western Finland. Journal of Rural Studies 25:87-97. http://dx.doi.org/10.1016/ j.jrurstud.2008.06.004 
Sandbrook, C., I. R. Scales, V. Bhaskar, and W. M. Adams. 2010. Value plurality among conservation professionals. Conservation biology 25:285-294.

Sayre, N. F. 2005. Ecological and geographical scale: parallels and potential for integration. Progress in Human Geography 29:276-290. http://dx.doi.org/10.1191/0309132505ph546oa

Sayre, N. F. 2008. Scale. Pages 95-108 in N. Castree, D. Demeritt, D. Liverman, and B. Rhoads, editors. A companion to environmental geography. Blackwell, Oxford, UK. http:// dx.doi.org/10.1002/9781444305722.ch7

Schultz, L., C. Folke, and P. Olsson. 2007. Enhancing ecosystem management through social-ecological inventories: lessons from Kristianstads Vattenrike, Sweden. Environmental Conservation 34:140-152. http://dx.doi.org/10.1017/ $\underline{\text { S0376892907003876 }}$

Smith, N. 2000. Scale. Pages 724-727 in R. J. Johnston, D. Gregory, G. Pratt, and M. Watts, editors. The dictionary of human geography. Fourth edition. Blackwell, Oxford, UK.

Snow, D. A., and R. D. Benford. 1992. Master frames and cycles of protest. Pages 133-155 in A. D. Morris and C. McClurg Mueller, editors. Frontiers in social movement theory. Yale University Press, New Haven, Connecticut, USA.

Strauss, A., and J. Corbin, editors. 1998. Basics of qualitative research: techniques and procedures for developing grounded theory. Sage, London, UK.

Swyngedouw, E. 1997. Neither global nor local: globalization and the politics of scale. Pages 137-166 in K. R. Cox, editor. Space of globalization. Guilford Press, New York, New York, USA.

Swyngedouw, E. 2000. Authoritarian governance, power, and the politics of rescaling. Environment and Planning D: Society and Space 18:63-76. http://dx.doi.org/10.1068/d9s

Swyngedouw, E. 2004. Scaled geographies: nature, place, and the politics of scale. Pages 129-153 in E. Sheppard and R. B. McMaster, editors. Scale and geographic inquiry: nature, society, and method. Blackwell, Oxford, UK. http://dx.doi. org/10.1002/9780470999141.ch7

Swyngedouw, E. 2007. Technonatural revolutions: the scalar politics of Franco's hydro-social dream for Spain, 1939-1975. Transactions of the Institute of British Geographers 32:9-28. http://dx.doi.org/10.1111/j.1475-5661.2007.00233.x

Termeer, C. J. A. M., A. Dewulf, and M. van Lieshout. 2010. Disentangling scale approaches in governance research: comparing monocentric, multilevel, and adaptive governance. Ecology and Society 15(4): 29. [online] URL: http://www. ecologyandsociety.org/vol15/iss4/art29/
Tuchman, G., editor. 1978. Making news. A study in the construction of reality. Free Press, New York, New York, USA.

Turner, M. D. 2006. Shifting scales, lines, and lives: the politics of conservation science and development in the Sahel. Pages 166-185 in K. Zimmerer, editor. Globalization and new geographies of conservation. Chicago University Press, Chicago, Illinois, USA.

Turner, M. G. 1989. Landscape ecology: the effect of pattern on process. Annual Review of Ecology and Systematics 20:171-197. http://dx.doi.org/10.1146/annurev.es.20.110189.001131

van Lieshout, M., A. Dewulf, N. Aarts, and C. Termeer. 2011. Do scale frames matter? Scale frame mismatches in the decision making process of a "mega farm" in a small Dutch village. Ecology and Society 16(1): 38. [online] URL: http:// www.ecologyandsociety.org/vol16/iss1/art38/

Verloo, M. 2005. Mainstreaming gender equality in Europe. A critical frame analysis approach. Greek Review of Social Research 117:11-34.

Zimmerer, K. S. 2000. The reworking of conservation geographies: nonequilibrium landscapes and nature-society hybrids. Annals of the Association of American Geographers 90:356-369. http://dx.doi.org/10.1111/0004-5608.00199

Zimmerer, K. S. 2006. Cultural ecology: at the interface with political ecology - the new geographies of environmental conservation and globalization. Progress in Human Geography 30:63-78. http://dx.doi.org/10.1191/0309132506ph591pr 
Appendix 1. Case study countries.

Finland is a northern European country and Greece a southern one, with, accordingly, different species, habitats, and ecosystems. However, the two countries share a loss of biodiversity, mainly due to non-sustainable and intensive productive activities such as agriculture, stock farming, and forestry (Auvinen et al. 2007, NCESD 2008). In both countries, the expansion of protected areas has been both remarkable, and significantly driven by EU conservation policy, over the last two decades. In addition, both countries have seen similar changes in line with the new public management (NPM) policies and neoliberalization processes in environmental governance (including biodiversity) occurring throughout the EU in recent decades (Sairinen 2000, Apostolopoulou and Pantis 2010, Apostolopoulou et al. 2012a, 2012b). In principle, biodiversity-governing structures have the same elements: environmental administration is structured through national, regional, and local authorities, where the dominant expertise tends to be in natural sciences. However, both countries have taken steps toward multilevel and networked governance arrangements through the establishment of various multilevel and multi-sector cooperation networks and public-private partnerships.

On the other hand, the economic context is different at present, with a recession in Finland and a crisis in Greece, resulting, inter alia, in limiting of resources for conservation. In Greece, the latter, in combination with the chronic absence of a conservation strategy (Apostolopoulou and Pantis 2009), has led to a situation wherein biodiversity governance focuses mainly on establishment of a national network of protected areas whereas on-theground integration of biodiversity objectives into other policies has been rather limited. In Finland, where a strategy does exist, policy integration has made more progress, with attempts to integrate biodiversity issues into land uses, planning, and sectoral policies, e.g., for forestry and agriculture (Paloniemi and Varho 2009), however conflicting interests still exist.

The aim in arranging focus groups in two EU member states was to explore the variety of discourses on biodiversity conservation and thus get a fuller general picture of the current scale challenges in European biodiversity policy and governance.

We should note that this qualitative study is part of a wider research project focusing on five case study countries, including Greece and Finland, triangulating and integrating both qualitative and quantitative material and methods (on such mixed methodology see Johnson et al. 2007, Denscombe 2008, Tapio et al. 2011). When designing the study, selecting its theoretical perspectives, and operationalizing the questions and arguments for the discussions, we benefited from detailed document analysis of national biodiversity policies and policy instruments for generating themes for focus groups and interpretation of the results to reflect dominant policy discourses in both Finland and Greece.

\section{REFERENCES}

Apostolopoulou, E., and J. D. Pantis. 2009. Conceptual gaps in the national strategy for the implementation of the European Natura 2000 conservation policy in Greece. 
Biological Conservation 142:221-237.

Apostolopoulou, E., and J. D. Pantis. 2010. Development plans versus conservation: Explanation of emergent conflicts and state political handling. Environment and Planning A 42:982-1000.

Apostolopoulou, E., E. Drakou, and J. D. Pantis. 2012a. Unraveling stakeholders' discourses regarding sustainable development and biodiversity conservation in Greece. Pages 405-430 in C. Ghenai, editor. Sustainable Development-Policy and Urban Development - Tourism, Life science, Management and Environment. InTech Publications, Croatia. URL: http://www.intechopen.com/source/pdfs/29238/InTechAunraveling_stakeholders_discourses_regarding_sustainable_development_and_bi odiversity_conservation_in_greece.pdf.

Apostolopoulou, E., E. Drakou, F. Santoro, and J. D. Pantis. 2012b. Investigating the barriers to adopting a "human-in-nature" view in Greek biodiversity conservation. International Journal of Sustainable Development and World Ecology, in press.

Auvinen, A. P., M. Hildén, H. Toivonen, E. Primmer, J. Niemelä, K. Aapala, S. Bäck, P. Härmä, J. Ikävalko, E. Järvenpää, H. Kaipiainen, K. T. Korhonen, H. Kumela, L. Kärkkäinen, J. Lankoski, M. Laukkanen, I. Mannerkoski, T. Nuutinen, A. Nöjd, P. Punttila, O. Salminen, G. Söderman, M. Törmä, and R. Virkkala. 2007. Evaluation of the Finnish National Biodiversity Action Plan 1997-2005. Monographs of the Boreal Environment Research 29:1-55.

Denscombe, M. 2008. Communities of practice: A research paradigm for the mixed methodology. Journal of Mixed Methods Research 2:270-283.

Johnson, R. B., A. J. Onwuegbuzie, and L. A. Turner. 2007. Towards a definition of mixed methodology research. Journal of Mixed Methods Research 1:112-133.

NCESD. 2008. The state of the environment 2008. National Center for the Environment and Sustainable Development (EKPAA), MEPPW, Athens, Greece. [online] URL: http://www.ekpaa.greekregistry.eu/index.php?option=com_content\&view=catego ry\&layout=blog\&id=49\&Itemid=106\&lang=el.

Paloniemi, R., and V. Varho. 2009. Changing ecological and cultural states and preferences of nature conservation policy: The case of nature values trade in south-western Finland. Journal of Rural Studies 25:87-97.

Sairinen, R. 2000. Regulatory reform of Finnish environmental policy. Dissertation. Helsinki University of Technology, Espoo, Finland. 
Tapio, P., R. Paloniemi, V. Varho, and M. Vinnari. 2011. The unholy marriage? Integrating qualitative and quantitative information in Delphi processes. Technological Forecasting \& Social Change 78:1616-1628. 
Appendix 2. Questions and statements for the eight focus groups in Greece and Finland.

The questions have been asked once in each country. In some cases they have been localized to better reflect the participants of focus groups. Questions are referred as follows: C: common questions, S: stakeholders questions, E: experts questions.

\section{General scale-related questions.}

1. a. Scale-related issues have received considerable attention the last decade. What do you consider to be the relevance of scale-related issues to biodiversity conservation? $\mathrm{b}$. How would you define the concept of scale in the context of biodiversity conservation? (C)

2. a. Give one example of a conservation policy that has been very successful in taking into account scale aspects. b. If a policy is designed to take scale into account, it should also be able to address scale challenges when implemented in practice. What are the main two key constraints that such "scale sensitive" policies have to deal with during implementation? (C)

3. Which is the most important scale challenge of biodiversity conservation? (C)

4. Give one example of a policy that has been most successful in addressing scale-related challenges in practice. Is this an important factor for policy success/failure or not? (S)

5. Is scale more an objective issue or a social construction? (E)

6. How do you define a conservation policy that is sensitive to scale? What primary characteristics should such a policy have? (E)

7. a. How would you define a scale mismatch? What are the causes and consequences of such mismatches? b. Will the uncertainty and complexity involved in biodiversity conservation inevitably create scale mismatches? (E)

8. Can scale be defined in an interdisciplinary way? And if so, how? (E)

9. Is there a gap between the generalized understanding produced by formal science and the practice-based understanding produced in "traditional" ecological knowledge? (E)

\section{Scale challenges of current policies and instruments driving the processes of designating and managing conservation areas.}

1. Do biodiversity policies and regulations on EU, national, and regional jurisdictional scales complement each other in your region? (C)

2. Biodiversity problems emerge differently in spatial, temporal and administrative scales, and these scales are ignored in the biodiversity policy of our country. (C)

3. Cross-level institutional and policy interplay is influenced by power dynamics. (C)

4. The cost and benefits of biodiversity policies are equally distributed across scales. (C)

5. Asymmetry in access to information can be bypassed by developing cross-level networks of community-based organizations and advocacy groups. (C)

6. There is often a mismatch between conservation objectives and management jurisdictions. (C)

7. The management of Natura 2000 sites should be based on fixed and rigid rules. (C)

8. Can cross-level governance structures such as management agencies address scale challenges? (S) 
9. Which stakeholders are (and should) be included in the governance and management of conservation areas? (S)

10. Has delegation of responsibilities for Natura 2000 management to regional institutions made Natura 2000 implementation sensitive to demands at local and regional levels? (S)

11. Are there time perspectives in conservation areas management? (S)

12. Do conservation area networks (e.g., Natura 2000) address the ecological complexity across jurisdictions? (S)

13. On the basis of which criteria have the boundaries of conservation areas and their zoning systems been decided? (S)

14. Does the management of conservation areas recognize the complexity, interconnectedness and dynamic characteristics of ecological and social systems? (What are the pivotal ecological processes and functions currently recognized in management? How does the present system deal with change and disruption? Is management consistent or variable across your area? Give examples). (E)

\section{Scale challenges related to the relationship of conservation areas to surrounding areas and to the integration of conservation with other policies.}

1. Biodiversity conservation cannot be ensured only by the designation of conservation areas without the integration of the biodiversity dimension into other policy sectors. (C)

2. In achieving integrated land management several conflicting policy goals, interests and values would have to be integrated. In this case, which should be the first priority? (C)

3. Fragmentation of institutional responsibilities is one of the main barriers in integrating conservation into other policy sectors. (C)

4. We need more coordination and cooperation between European, national and regional policies and relevant administrative bodies. Which factors are crucial for this? (C)

5. Building up a Green infrastructure as well as implementing climate change adaptation tools is essential in encouraging ecological connectivity in our country but remains a major challenge. (C)

6. The goal of management may cause mismatches if it is a purely ecological or purely social and not social-ecological. (S)

7. Is management of protected areas adjusted to the management of neighboring areas and to the wider landscape context? (S)

8. A possible way to reduce scale mismatches is to formulate management strategies and governance structures that focus on the social-ecological system and not solely on the social or the ecological system. What would be the implications of such an approach for research questions, methods, and practices? (E) 
Appendix 3. The outcomes of frame analysis regarding framing scale challenges as derived from scientific knowledge gaps. The numbers within parentheses indicate how many participants can be attributed to each code. GR refers to the participants of the focus group discussions in Greece and FIN refers to those in Finland.

Scale-related problems

Codes

(Diagnosis and roles of actors)

Mismatches between conservation objectives and human action (in terms of time, space, knowledge)
Problems in choosing boundaries and implementing zoning plans within conservation areas
Underestimation of the way that scale challenges are related to justice and power
There is a limited understanding of the scale-dependence of diversity components (GR: 7; FIN: 7)

Political and economic criteria are emphasized when deciding the size of a conservation area (GR: 6; FIN: 7)

Knowledge about nonlinear ecological processes at different scales is incomplete (GR: 5; FIN: 4)

Limited number of long-term and large-scale experiments on the effects of biodiversity components on ecosystem functioning across spatial and temporal scales (GR: 3; FIN: 2)

Decisions are not based on systematic conservation planning tools and software, e.g., Zonation, Marxan (GR: 3; FIN: 1)

Conservation biologists should discuss and decide the ideal size (large, small) of a conservation area (GR: 5; FIN: 6)

The impacts of climate change on species richness and/or fitness across spatial-temporal scales are not known or taken into consideration (GR: 5; FIN: 5)

Decisions based on administrative borders do not support optimal conservation scaling (GR: 6; FIN: 4)

There is not enough ecological data, e.g., long-term, at a suitable resolution, on the immigration and dispersal of species, available to design conservation areas (GR: 7; FIN: 2)

The minimum spatial scale that is necessary to ensure maintenance of biodiversity and ecosystem functions is ignored (GR: 2; FIN: 3)

Issues of justice and power, even if they definitely exist, are not directly related to scale challenges (GR: 7; FIN: 6)

Gaps in designing different policies and management measures 
conservation policies across different governance and/or administrative levels

Problems in integrating the biodiversity dimension into other policies across different governance and/or administrative levels at different spatial scales (GR: 7; FIN: 5)

Limited information exchange across different governance levels (GR: 7; FIN: 2)

Environmental administration and experts/academics do not discuss issues enough together (GR: 5; FIN: 4)

Lack of ecological expertise in environmental administrations (GR: 7; FIN: 1)

Absence of scientifically based policy instruments ensuring regional connectivity (GR: 7; FIN: 6)

Current environmental challenges, such as climate change and biodiversity loss, have not been taken seriously in other policy sectors (GR: 5; FIN: 6)

Environmental administrations are not influential enough over other administrative sectors for increasing the extent of protected areas (GR: 5; FIN: 5)

Policy integration is being approached as an organizational issue whereas it is primarily a knowledge issue (GR: 3; FIN: 7)

Policy integration is ineffective because of the absence of experts of all relevant disciplines (GR: 4; FIN: 5)

Solutions to identified problems (Prognosis and roles of actors)

Resolving mismatches between conservation objectives and human action (in terms of time, space, knowledge)
Policies prioritized in line with ecological (expert) knowledge (GR: 7; FIN: 8)

More "scale-sensitive" ecological data and knowledge, e.g., through more fieldwork and more systematic data sets at several scales (GR: 6; FIN: 5)

More dynamic understanding of ecosystems functions for dealing with environmental change (GR: 3; FIN: 8)

Support for standardized, rigorous, and objective scalerelevant methods and procedures for site selection and designation (GR: 5; FIN: 6)

Effective communication between local conservation actions 
How to choose boundaries and implement zoning plans within conservation areas

Acknowledgment of the way that scale challenges are related to justice and power

Effective coordination of conservation policies across different governance and/or administrative levels

Integration of the biodiversity dimension into other policies across different sectors, governance and planning at various administrative levels (GR: 4; FIN: 6)

Defining optimal zoning within protected areas through scientifically sound approaches (GR: 7; FIN: 5)

Systematic use of geographic information systems (GIS) for mapping species and habitats distribution (GR: 6; FIN: 4)

Regulate harmful human impacts on biodiversity through zoning plans (GR: 5; FIN: 3)

The size of the protected area should be related to its ecological significance (GR: 4; FIN: 3)

Strict measures and definition of no-entry zones at the core of protected areas with rich biodiversity (GR: 5; FIN: 2)

Environmental administrations that are rationalized and base their decisions on scientific reasoning should be strengthened (GR: 7; FIN: 7)

Better information provision about the ecological aspect of conservation to local people and/or stakeholders (GR: 7; FIN: 7)

Effective communication of scientific knowledge between experts and administrations (GR: 7; FIN: 8)

Environmental education programs at all levels to sensitize citizens to the benefits of biodiversity conservation (GR: 7; FIN: 7)

The main responsibility should lie with a central coordination scheme that will have a scientifically sound biodiversity strategy (GR: 4; FIN: 5)

Appreciation of international conservation efforts such as Natura 2000 that enforce actions at national level (GR: 3; FIN: 5)

The choice of the ideal responsible institution for conserving biodiversity should be based on its expertise (GR: 3; FIN: 4)

More systematic use of land use and conservation planning tools (GR: 7; FIN: 8)

Integration of the dimension of biodiversity conservation into all levels of environmental legislation according to a general 
Designing new conservation areas and ensuring connectivity between areas in accordance with the principles of conservation biology (GR: 7; FIN: 6)

Larger spatial scales should be taken into consideration to improve connectivity between seminatural habitats, in river basins, forest sites, etc. (GR: 5; FIN: 6)

Interdisciplinary approaches during policy implementation and dominance of natural sciences during policy designation (GR: 6; FIN: 4) 
Appendix 4. The outcomes of frame analysis regarding framing scale challenges as derived from limited fit. The numbers within parentheses indicate how many participants can be attributed to each code. GR refers to the participants of the focus group discussions in Greece and FIN refers to those in Finland.

Scale-related problems (Diagnosis and roles of actors)

Mismatches between conservation objectives and human action (in terms of time, space, knowledge)

Problems in choosing boundaries and implementing zoning plans within conservation areas
Policies are implemented according to administrative boundaries and the latter do not coincide with the boundaries of natural resources (GR: 13; FIN: 11)

Geographical areas of management institutions responsible for the protection and the protected area itself or the conservation objective do not match (GR: 12; FIN: 10)

Time scale of conservation practices (e.g., short-term implementation periods, changes in compositions of responsible agencies and in content of policies) follow human timelines, e.g., electoral cycles (GR: 10; FIN: 8)

The short-term implementation time of policies hinders commitment to long-term management efforts, e.g., certificates of organic farming, short-term project funding, annual management plans (GR: 6; FIN: 5)

Models and scientific predictions about biodiversity loss are not translated into information that can predict local impacts and guide local conservation actions (GR: 6; FIN: 5)

Administrative and legal boundaries, e.g., division of policy sectors, property rights, ownership titles, dominate over ecological processes when defining boundaries (GR: 11; FIN: 10)

The boundaries of protected areas do not simultaneously capture natural boundaries, administrative borders, and human activities (GR: 11; FIN: 10)

The diversity of laws and policy sectors governing human activities do not always match the various drivers of biodiversity loss (GR: 9; FIN: 11)

Borders of protected areas and zoning plans do not match with often larger (or smaller) spatial boundaries of natural systems composing of hierarchical and complex ecological structures (GR: 5; FIN: 5) 
Underestimation of the way that scale challenges are related to justice and power

Ineffective coordination of conservation policies across different governance and/or administrative levels

Problems in integrating the biodiversity dimension into other policies across different governance and/or administrative levels
Most policies are implemented following a top-down and not a bottom-up approach (GR: 13; FIN: 10)

Stakeholders that are involved in decision making processes or participatory procedures often do not represent the groups and activities that are located within conservation areas (GR: 11; FIN: 9)

The relationship between the EU level and the national level is a relationship of supervision and control, as it is between a ministry and a lower administrative level (GR: 11; FIN: 3 )

The implementation of policy takes place at lower administrative levels, e.g., by local agencies or regional authorities, but the funding is allocated at national level without the participation of lower levels (GR: 5; FIN: 2)

Mismatch between international or European obligations and national legislation as well as between national legislation and regional administrative guidelines, organization cultures and practices (GR: 11 ; FIN: 8)

Decisions are being made at top levels, e.g., EU, and they cannot be implemented at lower levels because of lack of resources, capabilities, or legitimacy deficit (GR: 9; FIN: 3)

Innovations made at lower levels are ignored at higher levels, e.g., EU and national, and thus they do not receive resources, capabilities, or official support (GR: 2; FIN: 4)

Governance scale does not exist in the sense that intermediate levels and/or communication efforts between existing levels are too weak (GR: 4; FIN: 1 )

There is not enough communication between the authorities responsible for the conservation of protected areas and those that are responsible for surrounding areas (GR: 13; FIN: 9)

Subsidies for green development and environmentally friendly activities do not match spatially and temporally with conservation objectives (GR: 12; FIN: 9)

Absence of concrete and powerful coordinating mechanisms, e.g., planning instruments or economic incentives, across sectors and state administrations (GR: 12; FIN: 3 )

Division of responsibilities does not follow the spatial patterning of conservation problems rendering impossible the 
effective cross-sectoral coordination (GR: 5; FIN: 3)

Fragmentation of governance scale, e.g., fragmentation of responsibilities or authorities, can be responsible for fragmentation of habitats and ecosystems (GR: 3; FIN: 3)

Solutions to identified

problems

(Prognosis and roles of actors)

Resolving mismatches between conservation objectives and human action (in terms of time, space, knowledge)

How to choose boundaries and implement zoning plans within conservation areas

Acknowledgment of the way that scale

Match policy instruments at different governance levels to the scale-dependence of drivers causing biodiversity loss (GR: 12; FIN: 11)

Participatory institutions and decision making structures should refer to the same spatial area (GR: $11 ;$ FIN: 8)

Alignment of governance structures and policy instruments to ecological borders (GR: 10; FIN: 9)

Scientific research should inform administration to find the optimal governance level for handling the conservation problem in hand (GR: 5; FIN: 4)

Transboundary cooperation for migratory species, pollution issues, and global climate change mitigation (GR: 5; FIN: 2)

Governing institutions should match the borders of conservation areas (GR: 11; FIN: 8)

Governing institutions should match the borders of ownership (GR: 7; FIN: 10)

Boundaries of protected areas and conservation zones should match natural boundaries (GR: 9; FIN: 8)

Better matching of the borders of management institutions and natural resources on the basis of the results of crossadministrative communication (GR: 6; FIN: 7)

Better matching of the borders of management institutions and natural resources on the basis of the results of systematic scientific monitoring (GR: 5; FIN: 3)

Economic incentives should be used to compensate the actual and potential costs of conservation to local people from national 
challenges are related to justice and power

Effective coordination of conservation policies

across different governance and/or administrative levels
Integration of the biodiversity dimension into other policies across different sectors, governance, and/or administrative levels budget (GR: 11; FIN: 12)

Citizens should be educated about the fact that global or national benefits of biodiversity are more important than shortterm local interests (GR: 11; FIN: 7)

States should carry responsibility for conservation, but also share power through increased communication between administrative levels and the private sector (GR: 6; FIN: 5)

The extent of human activities that is restricted because of conservation measures should be defined in a spatially explicit way (GR: 5; FIN: 6)

Identification of the ideal administrative level for each decision and action (GR: 11; FIN: 10)

State support for multilevel institutions with representatives from each governance sector and level (GR: 11; FIN: 9)

More meaningful cooperation between EU and national levels (GR: 11; FIN: 5)

Clear defined responsibilities and authorities for each administrative level and support for them from other sectors and levels through increased communication (GR: 7; FIN: 5)

Jurisdictional levels should be selected according to the scale of the legislation, e.g., national level should be responsible for EU responsibilities (GR: 6; FIN: 2)

Broadening the "classic" conservation approach (establishment of protected areas) to areas surrounding the strictly protected areas and the areas between them (GR: 7; FIN: 10)

Environmental education to change people's attitudes and behavior and increase personal commitment (GR: 12; FIN: 5)

It is a national responsibility to protect an area of international biodiversity significance and administrative arrangements should ensure that this responsibility cannot be overridden by short-term local interests (GR: 8; FIN: 1)

Economic instruments should be used in a more "scalesensitive" way, e.g., implemented at the level which is most relevant for each conservation goal (GR: 5; FIN: 4)

Incentives and sanctions for the integration of biodiversity 
conservation with other policy sectors must be under the authority of national level because they refer to international obligations (GR: 4; FIN: 2) 
Appendix 5. The outcomes of frame analysis regarding framing scale challenges as derived from existing power relationships and learning processes. The numbers within parentheses indicate how many participants can be attributed to each code. GR refers to the participants of the focus group discussions in Greece and FIN refers to those in Finland.

Scale-related problems

Codes

(Diagnosis and roles of actors)

Mismatches between Conceptual and geographic boundaries between the objects conservation objectives and human action (in terms of time, space, knowledge)

Problems in choosing boundaries and implementing zoning plans within conservation areas of conservation and human communities are too often set arbitrarily (GR: 9; FIN: 8)

In defining conservation goals the way that social and natural scales coproduce each other is either ignored or not sufficiently taken into account (GR: 8; FIN: 8)

Governance is responsive to market and not environmental dynamics (GR: 7; FIN: 7)

There is only a limited position for social learning in integrating different types of knowledge and conservation policy across scales (GR: 6; FIN: 9)

Research is not sufficiently directed toward investigating the role of social-ecological change in the production of scale (GR: 7; FIN: 6)

Human activities take place in a "unbounded" space that is fragmented for administrative reasons, inevitably creating mismatches (GR: 5; FIN: 6)

Institutionalizing technologies and practices leads to a static stabilization of conservation scaling (GR: 6; FIN: 5)

The persistence of systematic conservation planning leads to the ignorance of the role of social, economic, and cultural aspects in scale configurations (GR: 5; FIN: 3)

The overemphasis on the notion of boundaries in nature conservation is itself problematic (GR: 9; FIN: 9)

Decisions regarding boundaries and zones are insufficiently based on the spatial-temporal patterning of human-nature relationship (GR: 8; FIN: 8)

Dominant values and interests affect how boundaries and 
zoning are set, producing scale bias (GR: 8; FIN: 7)

Decisions on boundaries between conservation areas and human communities are often being made on the basis of a priori technical understandings of scale (GR: 8; FIN: 5)

Administrative levels are being approached as "natural" boundaries underestimating their historical, political, and economic underpinnings (GR: 5; FIN: 7)

Boundaries of natural resources, e.g., catchment areas, are not approached as both natural and anthropogeographical conditions (GR: 7; FIN: 5)

Underestimation of the way that scale challenges are related to justice and power

Ineffective coordination of conservation policies across different governance and/or administrative levels
Conservation scaling produces uneven ecological and social consequences at a variety of scales (GR: 6; FIN: 5)

Dominant approaches consider conservation scaling and relevant socio-spatial transformations as objective processes and not as outcomes of social struggles to gain control and access over resources (GR: 5; FIN: 5)

Conflicts over the appropriate scale for governing resources are insufficiently understood as linked to power struggles (GR: 6; FIN: 4)

Administrative levels, and power positions associated with them, are taken for granted (GR: 5; FIN: 5)

The production of networks of protected areas, e.g., Natura 2000 , is related to the rescaling of conservation interests in the context of European integration (GR: 4; FIN: 2)

Conservation scaling and scaling of resource-dependent livelihoods do not intersect (GR: 4; FIN: 2)

Biodiversity loss produced by drivers originating in other policy sectors cannot be solved only by conservation sector at any administrative level (GR: 9; FIN: 9)

Conservation goals set at higher administrative levels ignore the cross-scale character of the relationship between local communities and conservation objectives (GR: 6; FIN: 7)

Ignorance of the fact that the choice of the scale is related to the societal problem with which we have to deal (GR: 4; FIN: 3) 
Problems in integrating the biodiversity dimension into other policies across different governance and/or administrative levels

Solutions to identified problems (Prognosis and roles of actors)

Resolving mismatches between conservation objectives and human action (in terms of time, space, knowledge)

How to choose boundaries and implement zoning plans within conservation areas
Fragmentation of governance is often used as an excuse to hide the contradictory character of policies across sectors and administrative levels (GR: 8; FIN: 4)

Too often biodiversity is interpreted based on species, and the more holistic approach of ecosystems and socialecological systems is missing (GR: 6; FIN: 5)

Institutionalized organizational practices often lend inertia to power structures creating a difficult context for rescaling conservation through social learning (GR: 6; FIN: 4)

Approaching protected areas' establishment as the creation of social-ecological settings with specific, albeit dynamic, temporal and spatial characteristics (GR: 8; FIN: 8)

Approaching drivers of biodiversity loss as drivers of social-ecological change with specific, albeit dynamic, temporal and spatial characteristics (GR: 7; FIN: 8)

Approaching mismatches as outcomes of the inherent contradiction of dominant policies between conservation and promoting economic growth (GR: 7; FIN: 8)

Shifting research toward the exploration of the way that ecological and social change influence each other in space and time (GR: 6; FIN: 6)

Approaching mismatches in a dynamic way since the notion of mismatch is changing due to social-ecological change in space and time (GR: 5; FIN: 4)

Integrating dynamic ecological concepts into current static conceptualizations of ecological scale to guide conservation scaling (GR: 5; FIN: 3)

Boundaries between natural resources and human communities should be decided through democratic, participatory processes and negotiations (GR: 8; FIN: 6)

Administrative borders should not be approached as a priori 
given natural entities (GR: 6; FIN: 6)

Boundaries of conservation should be flexible, dynamic, and multidimensional (GR: 5; FIN: 5)

Explicitly incorporate lay knowledge to understand how the spatial patterning of the relationship between biodiversity and people has evolved over time (GR: 4; FIN: 3)

Shift research and policy focus toward unraveling the spatial patterning of human-environment interaction (GR: 4; FIN: 3)

Acknowledgment of the way that scale challenges are related to justice and power

Effective coordination of conservation policies across different governance and/or administrative levels

Integration of the biodiversity dimension into other policies across different sectors, governance and/or administrative levels
Approaching scales as dynamic and evolving, and exploring the roles and power positions of actors in producing them (GR: 9; FIN: 9)

Integrating local cultural and economic practices with local actors' perspectives into decision processes (GR: 6; FIN: 6)

Unravel how actors are scaling conservation issues to either claim or reject responsibility (GR: 5; FIN: 3)

Conservation scaling should be explicitly related to the issue of socio-spatial justice (GR: 3; FIN: 4)

An effective policy should take into account the continual interaction between scales (GR: 9; FIN: 9)

Conservation scaling should take place through democratic public participation to increase cross-scale cooperation of social groups in decision making processes (GR: 6; FIN: 4)

Administrative boundaries should be considered as an a priori problem and everything else as an effort to transcend them (GR: 4; FIN: 3)

Biodiversity conservation is part of a complex phenomenon affected by and affecting other sectors (GR: 8; FIN: 6)

Social and ecological connectivity as complementary goals (GR: 7; FIN: 6)

Creating and using integrative concepts, e.g., socialecological change, and methods to help communication and to increase commitment (GR: 5; FIN: 5)

Approaching learning as organizational endeavor to support 
better cross-level and cross-sectional cooperation (GR: 5; FIN: 3)

Encouraging conservation approaches based on the emergent and dynamic processes of social-ecological systems across scales toward integrative land and water management (GR: 3; FIN 2) 